\title{
Australian Football in America During COVID-19
}

\author{
James Bingaman \\ University of Delaware
}

\begin{abstract}
Despite its relative obscureness in the United States, Australian football has graced American airwaves since the 1990s. The outbreak of COVID-19 in the spring of 2020 paved the way for the Australian Football League to be one of the only professional sports leagues broadcasting games live on American television. Although the Australian Football League would later suspend the season, for at least one weekend, Australian football was the most popular sport in the United States. This short essay pulls from news articles, social media posts, and existing literature to explore this unique time in the American sports landscape by investigating the response to Australian football from fans, the response from media outlets, and the future directions of Australian football in the United States. The increase in exposure could help the Australian Football League become the next big spectator sport in the United States as well as help grow the game at a local, grassroots level.
\end{abstract}

Keywords: framing, nonnormative sports, social media, spectator sport

Australian football-also known as Australian Rules football, Aussie Rules, or "footy" - is the second oldest form of football in the world (Blainey, 2003) and is largely considered the national sport of Australia (Richardson, 2011). Although Australian football has been a late-night staple of sports networks like Entertainment and Sports Programming Network and Fox Sports since the 1990s, the sport enjoyed unparalleled attention in the United States during the spring of 2020 as the Australian Football League (AFL) decided to continue playing games amid the outbreak of COVID-19 (Barrett, 2020). In response to growing public concern, the league implemented new safety measures including reducing the length of the season, shortening games, banning spectators from stadiums, routinely washing the footballs, and removing the traditional handshake between captains at the start of each match. Although there was contentious public debate surrounding the continuation of sports amid a pandemic, the AFL season began on schedule on March 19, 2020 and included a slate of nine games ending on March 22, 2020.

The author (jbinga@udel.edu) is with the Dept. of Communication, University of Delaware, Newark, DE, USA. 
With sports effectively canceled in the United States, Australian football offered a welcome reprieve to sports fans in America who were suddenly faced with a grim future without sport. Between March 19 and the 22 of 2020, Google searches for Australian football in the United States were more popular than at any other time over the last 4 years (Google, 2020), marking a significant increase in attention of regular-season games and prompting the exploration of this unique time in U.S. sports. Though the league would later suspend the season, for one weekend, Australian football became the most popular sport in the United States. This essay uses news articles, social media posts, and existing literature to explore the response to Australian football from U.S. fans and media outlets, while also providing future directions for Australian football in the United States.

\section{Fan Response}

A total of five regular-season games were broadcast on Fox Sports- (AFL rights holder) affiliated channels in the United States. Games in the United States are primarily broadcast via Fox Soccer Plus, with one game a week being shown on Fox Sports 1 or Fox Sports 2. However, of the five games shown in the United States, three were moved to Fox Sports 1 to fill vacant timeslots, instantly increasing the exposure to a wider audience. Indifferent to the time difference, American sports fans took to Twitter to voice their infatuation with Australian football. For some, the sheer presence of live sports was enough to sustain their insatiable appetite. For others, this was their first time experiencing this new form of football, seemingly sparking intrigue. Likewise, pundits and journalists such as Joe Reedy (Associated Press), Greg Tepper (Fox Sports Southwest), and Chris Burke (The Athletic), who had been craving something to comment on, were suddenly "all-in" on Australian football and rallied their audiences around this late-night coverage. However, no response was more fervent than former Indianapolis Colt punter turned media personality, Pat McAfee.

McAfee (1.8 million followers), who has more than twice the Twitter followers as the AFL (720,000 followers), advocated for Australian football not only on his Twitter but on his other media platforms including YouTube and his podcast (Negrepontis, 2020). While his discovery of the game and subsequent commentary was quite entertaining for fans back in Australia, as a marketing strategy, it worked wonders in the United States, especially with McAfee essentially operating as a celebrity endorsement.

The effectiveness of athletic endorsements as a marketing strategy is well established (see Kim \& Cheong, 2011). Chen, Lin, and Hsiao (2012) note that the pairing of an athlete endorser and sporting event can influence attitudes toward those sporting events. As a former National Football League punter, McAfee is seen by fans as an expert in the skills needed to kick an oval-shaped football- the fundamental method of passing in Australian football. McAfee's endorsement served as a legitimization tool, meaning Australian football was no longer a latenight oddity; it was a proper form of football.

Although McAfee alone cannot single-handedly make Australian football popular in the United States, his social media advocacy, that continued well after the suspension of the AFL season, bypassed traditional news outlets (Lowes \& Robillard, 2018), catapulting Australian football into U.S. sports 
discourse. While this kind of advocacy can be influential, traditional news outlets are still needed to reinforce widespread acceptance and attitude change (Mitchell, Santarossa, \& Woodruff, 2018).

\section{News Media Response}

Framing relies on the assumption that increased media coverage determines issue salience and perception (Seltzer \& Dittmore, 2009). The response from news media outlets to Australian football was predominantly framed in two ways. Australian outlets were more likely to provide an outline of the game, the rules, or a brief history for new fans. Conversely, American news outlets used frames that focused less on the minutiae of the game and instead relied more on describing Australian football as a sport that could fill the sudden void felt by sports fans in the United States; a considerably larger-scale view of what Australian football could be to an American audience.

Just as McAfee did on social media, mainstream American news outlets began to treat Australian football as a legitimate sport, not just a cultural phenomenon. Acquavella (2020) of CBS Sports noted that "with all four of the major US sports leagues currently on hold, the AFL could prove to be a source of entertainment for American sports fans" (para. 4). Furthermore, Bonesteel (2020) of The Washington Post commented that "given that the sport is one of the few still playing amid the pandemic, global interest could spike" (para. 5). Some journalists even referred to Australian football as "America's new pastime" (Carson, 2020, para. 1).

As established in extant sports media literature, nationalistic bias is a common practice in American media outlets as it relates to the framing of sports and individual athletes (Angelini, Billings, \& MacArthur, 2012; Arth, Griffin, \& Billings, 2018). As an international sport, Australian football has rarely been discussed in U.S. media unless it relates to college and professional punters from Australia, a recent phenomenon (Bishara, 2018). Even though the AFL season was suspended after 1 week, the frames and narratives have since shifted in traditional news outlets to represent Australian football as its own sport. With many spectators relying heavily on mediated channels as an introduction to different sports (Angelini, Billings, MacAurther, \& Reichart-Smith, 2014), this is an important development for the continued success of Australian football in the United States.

\section{Response From AFL/USAFL}

Borges (2019) argued that "to succeed in a media society or be represented in a media culture, nonmedia actors have to adapt to this media logic" (p. 288). The AFL, having little media representation in the United States, took to social media to respond to the sudden surge in popularity among U.S. fans, effectively acting as their own media organization. One tweet read, "Dear [USA]. Thanks for watching \#AFLDonsFreo. [Heart] AFL. P.S. If you also find yourself outside of Australia, you can watch us here: watchafl.com" (Australian Football League, 2020). Not only did they direct these messages to new fans in the United States, but they prompted them to bypass the traditional gatekeepers of Australian football and instead suggested a transition to the league-owned media outlet. 
Stateside, the United States Australian Football League (USAFL) capitalized on the increase in exposure by live-tweeting and reaching out to new fans. To be successful on social media, organizations need to provide continuous communication and elicit social interaction (Thompson, Martin, Gee, \& Eagleman, 2014). The USAFL successfully demonstrated this strategy by making sure to reach out to as many fans as possible, comment on news stories related to Australian football, and provide information to spectators (e.g. rules, video demonstrations, and local club information). Over the course of 3 days, the USAFL increased their Twitter following by more than 25\% (United States Australian Football League, 2020). The use of social media as a marketing tool not only helped the AFL gain traction in the U.S. spectator market, but it allowed the USAFL, which has 45 clubs across the United States, recruit and expand their grassroots movement in the hopes of increasing participation at the local club level.

\section{Future Directions for Australian Football}

\section{The Next Big Spectator Sport}

Global expansion is something the AFL has actively sought out for more than 20 years (Carney, 2019). With viewing behavior of televised sports being positively correlated with live sports attendance (Zhang, Pease, \& Smith, 1998), this newfound adoration in the United States comes at an opportune time as the AFL was already looking to host live matches in the United States in 2021 or 2022 (Morris, 2020). Not only would expansion into the United States benefit the AFL, but it would also benefit sports fans in the United States.

Sports networks - both in the traditional sense and newer mobile video streaming and over-the-top internet options (Hutchins, Li, \& Rowe, 2019)—are increasing year after year (Lajoie, 2019), with the options to fill timeslots becoming increasingly more expensive. According to PledgeSports ("Biggest TV Rights," 2018), the cost of broadcasting the three major sports networks (between $\$ 12.4$ billion and $\$ 39.6$ billion) pales in comparison with what it costs to broadcast the AFL (\$2 billion). While there are significant differences in the media structures of the United States and Australia, the AFL potentially provides U.S. sports networks with a cheaper alternative. Fox Sports recently lost the rights to the Champions League, UFC (Ultimate Fighting Championship), BIG3 basketball, and XFL (Reedy, 2019). Filling in timeslots with Australian football allows Fox Sports to be the bearer of this new and exciting form of football that has fans clamoring for more.

However, the key to sustained success as a spectator sport resides not in the mediated presentation of the sport, but in that sport's ability to connect with fans. Rong (DanDan) Hua, Digital-Media Manager of the National Football League's China office, claims that local stories and connections with audiences are integral for viewership (Zheng, 2018). Mason Cox, an American-born player in the AFL and former basketball player at the Oklahoma State University, was recruited at a combine event in Los Angeles and seized an opportunity to play in Australia, becoming an overnight cult-like hero (Tang, 2018). The recent surge in attention for Australian football led Cox to tweet that, "this might be @ AFL best opportunity at growing the game worldwide ..." (Cox, 2020). Committed fans are more emotionally involved and responsive than nonfans (Gantz \& Wenner, 1995), so 
finding ways to connect Australian football to an American audience is essential for survival in the overcrowded U.S. sports market. However, these success stories will only become more prolific if there is sustained and continued development and participation at the local level.

\section{Increase in Participation}

Media exposure of nonnormative sports not only facilitates acceptance, but it can help drive development and participation at the local level (Woods, 2019). The USAFL is hoping that increased media exposure generates an increase in participation for clubs. While there are several ways to increase participation, one direction the USAFL should investigate is developing a following on college campuses.

Participation in campus recreational sports has been linked to increases in sports participation, school retention, health and wellness, and student learning outcomes (Forrester, 2015). The way rugby, a similar nonnormative sport, has developed across college campuses serves as an exemplar and template that the USAFL should seek to emulate. While expanding on college campuses would be advantageous for the USAFL, continued participation at the club level is also needed. Since there is no existing literature relating to Australian football participation in the United States, past studies examining the motivations to play rugby demonstrate potentially replicable findings. Dong, Zhang, Choe, and Pugh (2013) note that long-term commitment, skill improvement, and cultural awareness are all motivations to play rugby, while Fields and Comstock (2008) assert that rugby validates participants' "sense of strength and power beyond what American sensibilities generally allowed" (p. 15). With thousands of participants and close to 50 clubs across the country, future research should investigate the motivations behind playing Australian football in the United States.

\section{Final Thoughts}

Amid a terrifying pandemic that led to the cancellation of sports across the globe, the continuation of the AFL, for even a week, should be viewed as somewhat of a positive outcome. Not only did this benefit the league's popularity on social media, but with the games being moved from behind a paywall, the league successfully auditioned for a starting spot on the Fox Sports roster (to borrow a sports metaphor). With the AFL resuming their season in early June (Prestipino, 2020), ahead of some of the major sports leagues in the United States, this one weekend in March could be the catalyst that leads to prolonged interest in Australian football by Americans. Although Australian football has been on American television since the 1990s, this recent increase in exposure feels different; almost like Australian football will finally get the attention that the second oldest form of football deserves.

\section{References}

Acquavella, K. (2020, March 21). Coronavirus: What to know about the Australian Football League, who plan to play in empty stadiums this season. CBS Sports. Retrieved 
from https://www.cbssports.com/general/news/coronavirus-what-to-know-about-theaustralian-football-league-who-plan-to-play-in-empty-stadiums-this-season/

Angelini, J.R., Billings, A.C., \& MacArthur, P.J. (2012). The nationalistic revolution will be televised: The 2010 Vancouver Olympic Games on NBC. International Journal of Sport Communication, 5(2), 193-209. doi:10.1123/ijsc.5.2.193

Angelini, J.R., Billings, A.C., MacAurther, P.J., \& Reichart-Smith, L. (2014). Competing separately, medaling equally: Racial depictions of athletes in NBC's primetime broadcast of the 2012 London Olympic Games. Howard Journal of Communications, 25(2), 115-133. doi:10.1080/10646175.2014.888380.

Arth, Z.W., Griffin, D.J., \& Billings, A.C. (2018). (Inter)National pastime: Depicting nationality in local and national Major League Baseball broadcasts. International Journal of Sport Communication, 12(3), 354-370. doi:10.1123/ijsc.2018-0131

Australian Football League. (2020, March 21). Dear [USA], Thanks for watching \#AFLDonsFreo [heart]. AFL P.S. If you also find yourself outside of Australia, you can watch us here: watchafl.com More: afl.to/398aAfR. [Tweet]. Retrieved from https:// twitter.com/AFL/status/1241304289420537856

Barrett, D. (2020, March 18). It's on: AFL confirms round one will go ahead. Retrieved from https://www.afl.com.au/news/386263/it-s-on-afl-confirms-round-one-will-go-ahead

"Biggest TV Rights Deals in Sport." (2018, January). PledgeSports. Retrieved from https:// www.pledgesports.org/2018/01/biggest-tv-rights-deals-in-sport/

Bishara, M. (2018, August 30). NFL: How one school in Melbourne, Australia is reshaping gridiron. CNN. Retrieved from https://www.cnn.com/2018/08/30/sport/australia-nflpunting-factory-intl-spt/index.html

Blainey, G. (2003). A game of our own: The origins of Australian football. Melbourne, Australia: BlackInc.

Bonesteel, M. (2020, March 19). Australian rules football starts its season amid the coronavirus outbreak. The Washington Post. Retrieved from https://www.washington post.com/sports/2020/03/19/australian-rules-football-rules/

Borges, F. (2019). Soccer clubs as media organizations: A case study of Benfica TV and PSG TV. International Journal of Sport Communication, 12(2), 275-294. doi:10. 1123/ijsc.2019-0001

Carney, S. (2019, February 14). AFL expansion strategy starts with world 9s this weekend. Ministry of Sport. Retrieved from https://ministryofsport.com.au/afl\%09expansionstrategy-starts-with-world-9s-this-weekend/

Carson, E. (2020, March 21). What is Aussie rules football? Reaction, rules to the only sport on TV during the coronavirus. Sporting News. Retrieved from https://www. sportingnews.com/us/australian-rules-football/news/what-is-aussie-rules-footballreaction-rules-only-sport-on-tv-during-coronavirus/1jvpzzpxhhn2s1uzkcsb8hrjnq

Chen, C.Y., Lin, Y.H., \& Hsiao, C.L. (2012). Celebrity endorsement for sporting events using classical conditioning. International Journal of Sports Marketing \& Sponsorship, 13(3), 209-219. doi:10.1108/IJSMS-13-03-2012-B005

Cox, M. [@masonsixtencox]. (2020, March 21). It is weird to think but this might be @ AFL best opportunity at growing the game worldwide...". [Tweet]. Retrieved from https:// twitter.com/masonsixtencox/status/1241253631602479104

Dong, E., Zhang, L., Choe, J., \& Pugh, S. (2013). Rugby union among middle-aged American men: An exploration. Leisure Studies, 32(2), 219-228. doi:10.1080/ 02614367.2012.748089

Fields, S.K., \& Comstock, R.D. (2008). Why American women play rugby. Women in Sport and Physical Activity Journal, 17(2), 8-18. doi:10.1123/wspaj.17.2.8

Forrester, S. (2015). Benefits of collegiate recreational sports participation: Results from the 2013 NASPA assessment and knowledge consortium study. Recreational Sports Journal, 39(1), 2-15. doi:10.1123/rsj.2015-0005 
Gantz, W., \& Wenner, L.A. (1995). Fanship and the television sports viewing experience. Sociology of Sport Journal, 12(1), 56-74. doi:10.1123/ssj.12.1.56

Google. (2020). [Interactive map showing interest over time for the search term "Australian football"]. Google Trends. Retrieved from https://trends.google.com/trends/explore? date=today\%205-y\&geo=US\&q=Australian\%20football

Hutchins, B., Li, B., \& Rowe, D. (2019). Over-the-top sport: live streaming services, changing coverage rights markets and the growth of media sport portals. Media, Culture \& Society, 41(7), 975-994. doi:10.1177/0163443719857623

Kim, K., \& Cheong, Y. (2011). The effects of athlete-endorsed advertising: The moderating role of the athlete-audience ethnicity match. Journal of Sport Management, 25(2), 143-155. doi:10.1123/jsm.25.2.143

Lajoie, D. (2019). The state of sports television: How to create the ultimate sports network in the ever-changing television landscape (Doctoral Dissertation). Retrieved from ProQuest Dissertations and Theses A\&I. (2235951339).

Lowes, M., \& Robillard, C. (2018). Social media and digital breakage on the sports beat. International Journal of Sport Communication, 11(3), 308-318. doi:10.1123/ijsc. 2018-0088

Mitchell, F.R., Santarossa, S., \& Woodruff, S.J. (2018). Athletes as advocates: Influencing eating-disorder beliefs and perceptions through social media. International Journal of Sport Communication, 11(4), 433-446. doi:10.1123/ijsc.2018-0112

Morris, T. (2020, March 3) Essendon's California dream: Dons want USA match for premiership points. Fox Sports. Retrieved from https://www.foxsports.com.au/afl/afl2020-essendon-and-gws-to-play-in-america-for-premiership-points-in-2021-of-2022/ news-story/63043ab4244171e819a850816fd14b01

Negrepontis, N. (2020, March 21). Swarm of American viewers turn to AFL to fill sporting void. SEN 1116. Retrieved from https://www.sen.com.au/news/2020/03/21/swarm-ofamerican-viewers-turn-to-afl-to-fill-sporting-void/

Prestipino, D. (2020, May 15). Eagles, Dockers swing back to AFL action on Gold Coast in mid June. The Age. Retrieved from https://www.theage.com.au/sport/afl/ eagles-dockers-swing-back-to-afl-action-on-gold-coast-in-mid-june-20200515-p54tbq. html

Reedy, J. (2019, May 1). Fox Sports 1 showing patience, growth with studio lineup. Associated Press. Retrieved from https://apnews.com/5ce025b37a1543b0ab26 dfc28294af38

Richardson, N. (2011). A national game: The history of Australian Rules football. The International Journal of the History of Sport, 28(13), 1916-1917. doi:10.1080/ 09523367.2011.620285

Seltzer, T., \& Dittmore, S.W. (2009). Down, set, frame: Second-level agenda building and the NFL Network carriage dispute. International Journal of Sport Communication, 2(3), 340-359. doi:10.1123/ijsc.2.3.340

Tang, S.B. (2018, October 8). How an American basketball player became a star in Australian Rules football. The New York Times. Retrieved from https://www. nytimes.com/2018/10/08/sports/mason-cox-football-australia.html

Thompson, A.J., Martin, A.J., Gee, S., \& Eagleman, A.N. (2014). Examining the development of a social media strategy for a national sport organisation: A case study of Tennis New Zealand. Journal of Applied Sport Management, 6(2), 42-63. Retrieved from https://research-repository.griffith.edu.au/bitstream/handle/10072/63604/96635_1.pdf

United States Australian Football League. [@USAFL1997]. (2020, March 22). So last night we were wondering if we were gonna hit 4,000 followers. Tonight we might hit 5,000. [Tweet]. Retrieved from https://twitter.com/USAFL1997/status/1241588909445976065

Woods, J. (2019). Normative bridges and barriers in the framing of emerging sports movements. Sociological Spectrum, 39(4), 234-249. doi:10.1080/02732173.2019.1669236 
Zhang, J.L., Pease, D.G., \& Smith, D.W. (1998). Relationship between broadcasting media and Minor League Hockey game attendance. Journal of Sport Management, 12(2), 103-122. doi:10.1123/jsm.12.2.103

Zheng, J. (2018). Interview with Rong (DanDan) Hua, digital media manager of the National Football League's China office. International Journal of Sport Communication, 11(3), 301-307. doi:10.1123/ijsc.2018-0094 